\title{
Lacunas entre a formação do nutricionista e o perfil de competências para atuação no Sistema Único de Saúde (SUS)
}

Cristina Garcia Lopes Alves(a)

Maria Regina Martinez ${ }^{(b)}$

Alves CGL, Martinez MR. Gaps between nutritionists' training and their skills profile for working within Brazilian National Health System (SUS). Interface (Botucatu). 2016; 20(56):159-69.

Nutritionists' work within the Brazilian National Health System (SUS) involves feeding and nutrition activities in institutional, primary care and health surveillance programs and policies, and envisages development of general and specific skills through academic training in accordance with the National Curricular Guidelines. Starting from analysis on a pedagogical course project, we reflected on nutritionists' training and their alignment with the guidelines that regulate the profession and their work within SUS. Fifteen disciplines within the field of public health were selected and subjected to content analysis. This revealed gaps relating to the presence or absence of certain subject matters among the lists. "Leadership" and "continuing education" skills were not identified in the project, even though these are necessary for nutritionists' training. In conclusion, the elements presented will be able to guide nutrition curricula that focus on training for work within SUS.

Keywords: Pedagogical project. Nutrition. Skills. Curricular guidelines.
A atuação do nutricionista no Sistema Único de Saúde (SUS) envolve atividades de alimentação e nutrição em políticas e programas institucionais, de atenção básica e vigilância sanitária, prevendo desenvolver competências gerais e específicas na formação acadêmica, conforme as Diretrizes Curriculares Nacionais (DCN). Partindo-se da análise de um projeto pedagógico de curso (PPC), refletiu-se sobre a formação do nutricionista e o seu alinhamento com as diretrizes que regem a profissão e sua atuação no SUS. Foram selecionadas e submetidas à análise de conteúdo, que revelou lacunas relacionadas à presença ou não de determinados conteúdos nas ementas, 15 disciplinas do campo da Saúde Coletiva. As competências "liderança" e "educação permanente" não foram identificadas no PPC, embora necessárias à formação do nutricionista. Em conclusão, os elementos apresentados poderão nortear os currículos de Nutrição, com foco em uma formação para atuação no SUS.

Palavras-chave: Projeto pedagógico. Nutrição. Competências. Diretrizes Curriculares.

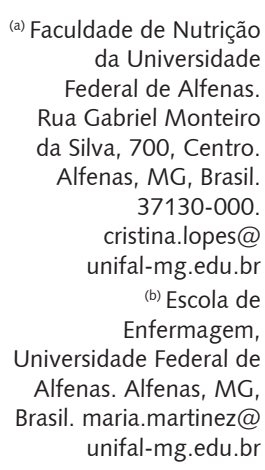

(a) Faculdade de Nutrição da Universidade Federal de Alfenas. Rua Gabriel Monteiro da Silva, 700, Centro Alfenas, MG, Brasil. 37130-000. cristina.lopes@ unifal-mg.edu.br

(b) Escola de Enfermagem, Universidade Federal de Alfenas. Alfenas, MG, Brasil.maria.martinez@ unifal-mg.edu.br 


\section{Introdução}

O Sistema Único de Saúde (SUS) foi instituído pela Constituição Federal de 1988, tendo uma dimensão verdadeiramente universal quando cobre indistintamente todos os brasileiros com diferentes níveis de atenção, de baixa a alta densidade tecnológica, além de serviços de vigilância sanitária de alimentos e de medicamentos, de vigilância epidemiológica, entre outros. No campo restrito da assistência à saúde, ele é responsável exclusivo por cento e quarenta milhões de pessoas, já que 48 milhões de brasileiros recorrem ao sistema de saúde suplementar, muitos deles acessando concomitantemente o SUS em circunstâncias em que o sistema privado apresenta limites de cobertura ${ }^{1}$.

A Política Nacional de Atenção Básica (PNAB) no SUS, garantindo o acesso universal aos serviços de saúde, é preferencialmente a primeira forma de atendimento à população². A interdisciplinaridade está prevista na PNAB e é assumida pelos profissionais, sendo percebida como ação concreta capaz de produzir mudanças no processo de trabalho ${ }^{3}$.

$\mathrm{Na}$ busca da integralidade da atenção, uma adequada inserção profissional do nutricionista favorece a promoção da saúde a partir da qualificação das ações de alimentação e nutrição, tendo como foco a saúde da família. Nas atividades desenvolvidas pelos nutricionistas que atuam na atenção básica há o predomínio de ações classificadas como de assistência, tratamento e cuidado e com grupos educativos, sendo caracterizadas como atividades de promoção da saúde. As ações de assistência individual e as atividades administrativas são menos frequentes, mas também previstas em sua atuação profissional ${ }^{4}$.

A Resolução CFN 380/2005, que dispõe sobre a definição das áreas de atuação do nutricionista e suas atribuições, estabelece que a sua atuação na saúde coletiva envolva atividades de alimentação e nutrição realizadas em políticas e programas institucionais, de atenção básica e de vigilância sanitária ${ }^{5}$, prevendo o desenvolvimento de competências gerais e específicas ao longo da sua formação profissional.

De acordo com a Câmara de Educação Superior do Conselho Nacional de Educação, as atuais Diretrizes Curriculares Nacionais (DCN) se constituem de orientações para a elaboração dos currículos que devem ser adotadas por todas as instituições de ensino superior, dentro da perspectiva de assegurar flexibilidade, diversidade e qualidade da formação oferecida aos estudantes, garantindo uma sólida formação básica e preparando o futuro graduado para enfrentar os desafios das rápidas transformações da sociedade, do mercado de trabalho e das condições de exercício profissional ${ }^{6}$.

As competências gerais, conforme definidas nas DCN, se referem a um conjunto de competências que deve promover, no aluno, a capacidade de desenvolvimento intelectual e profissional autônomo e permanente. Para os cursos de graduação em Nutrição, a formação desse profissional inclui possibilitar, aos graduandos, o exercício das seguintes competências gerais: Atenção à Saúde, Tomada de Decisões, Comunicação, Educação Permanente, Liderança, Administração e Gerenciamento 6 .

As DCN ainda destacam que os cursos de graduação e pós-graduação, no caso específico da Nutrição, devem contemplar a formação de profissionais que atendam às necessidades sociais em alimentação e nutrição em sintonia com os princípios do SUS ${ }^{6}$; portanto, é importante também considerar a adequação da formação profissional à Política Nacional de Alimentação e Nutrição PNAN?.

O termo "competência" é polissêmico e sua proposição no campo da educação é controversa. Neste trabalho, entende-se que as competências em si mesmas não são manifestações de conhecimentos, mas, sim, a sua utilização, integração e mobilização. Refletem uma capacidade de agir eficazmente em um determinado tipo de situação, apoiada em conhecimentos, mas sem limitar-se a eles ${ }^{8}$.

Conforme Recine et al. ${ }^{9}$, o desafio proposto pelas novas DCN, de formar um profissional generalista, dentro de uma perspectiva mais complexa, menos "biologicista", mais focada nas questões sociais e em sua inserção no SUS, com capacidade de leitura dos problemas locais, exige dos cursos a necessidade de incorporar, em seus projetos pedagógicos, uma série de novos conteúdos. A formação generalista transcende a atenção dietética, ampliando as competências e o espectro de atuação do nutricionista. Cresce a atuação dos nutricionistas na gestão de políticas públicas e na promoção da saúde e em diversos setores, como vigilância sanitária e fiscalização. 
O Projeto Pedagógico de Curso (PPC) é um documento normativo dos cursos de graduação, com informações acerca da concepção e estrutura do curso. Pode ser entendido como um instrumento de balizamento para o "fazer universitário", concebido coletivamente no âmbito da instituição, orientado para esta e para cada um de seus cursos. Deve oportunizar a construção da intencionalidade para o desempenho do papel social da instituição, centrando-se no ensino mas vinculando-se, estreitamente, aos processos de pesquisa e extensão. Com base na análise crítica do momento vivido, deve-se, ainda, configurar a visão pretendida, efetivando as ações, refletindo sobre elas, avaliando-as e incorporando novos desafios ${ }^{10}$.

É um grande desafio, para os cursos de graduação em Nutrição, traduzir as concepções previstas nas Diretrizes Curriculares em projetos pedagógicos, como uma linguagem oficial que norteará toda a formação. Esse desafio se amplifica quando se pensa em uma formação capaz de atender o desenvolvimento das competências necessárias para o nutricionista atuar no SUS.

Críticas têm sido formuladas em relação à formação do nutricionista, em virtude da sobrecarga de conteúdos voltados para as ciências biológicas, em detrimento de uma formação mais sólida em aspectos político-sociais. A carga horária destinada ao estudo das ciências humanas nos cursos de Nutrição apresenta um decréscimo percentual nas últimas quatro décadas, e o desvio dessas horas se dá, sobretudo, para disciplinas das áreas biológicas ${ }^{11}$, induzindo uma predominância do desenvolvimento de competências voltadas para a atenção à saúde no contexto da individualidade em detrimento da coletividade.

Este estudo buscou identificar as competências gerais a partir das ementas das disciplinas do projeto pedagógico de um curso de Nutrição de uma instituição pública de ensino, como forma de aprofundar a discussão sobre a formação acadêmica do nutricionista frente ao atendimento das diretrizes e dos princípios do SUS.

\section{Metodologia}

Trata-se de uma pesquisa documental, que se caracteriza pelo levantamento de dados restritos a documentos, escritos ou não. Esses são classificados segundo a fonte oriunda de: 1) arquivos públicos - municipais, estaduais e federais, arquivos particulares e fontes estatísticas; e 2) documentos escritos, iconografia, fotografias, objetos, canções folclóricas, vestuário e folclore ${ }^{12}$.

Para a realização desta pesquisa, foram utilizados como documentos: a Resolução CNE/CES n 5 de 2001, que institui as Diretrizes Curriculares Nacionais do Curso de Graduação em Nutrição (DCN); a Resolução CFN 380 de 2005, que dispõe sobre a definição das áreas de atuação do nutricionista e suas atribuições; e o Projeto Pedagógico do Curso de Nutrição da instituição de Ensino Superior da qual as autoras compõem o quadro funcional.

O Projeto Pedagógico do Curso (PPC), utilizado como objeto de análise neste estudo, se enquadra, de acordo com a classificação de Lakatos e Marconi ${ }^{13}$, como documento escrito, pois provém de fontes de arquivos particulares da instituição de Ensino Superior participante. Sua escolha por conveniência está relacionada ao interesse das autoras em colaborar com a reflexão sobre a adequação deste PPC ao desenvolvimento de competências voltadas para a atuação, no SUS, dos nutricionistas em formação.

O PPC utilizado foi implantado no ano de 2010 e tem uma carga horária total de 4143 horas, assim distribuídas: 3090 horas de formação acadêmica (por meio de aulas teóricas, práticas, teóricopráticas), 855 horas de estágios supervisionados, e 198 horas de atividades formativas. O tempo de integralização é de quatro anos e meio ou nove semestres; e o tempo máximo é de seis anos ou 12 semestres. Para a condução desta pesquisa, o projeto que deu origem ao estudo foi aprovado pelo Comitê de Ética e Pesquisa da Universidade Federal de Alfenas.

Os dados emergiram das ementas do PPC, que foram submetidas à análise de conteúdo atendendo aos pressupostos de Bardin ${ }^{14}$. Primeiramente, foram feitas várias leituras de todos os documentos analisados com a intenção de apreender suas particularidades. Na sequência, e com base nos conteúdos e terminologias encontradas na Resolução CFN 380/2005, selecionamos as disciplinas do PPC que estariam alinhadas às atribuições do nutricionista para a atuação na área de saúde coletiva. 
Iniciamos, então, o processo de identificação das categorias de codificação, ou seja, palavras ou termos que tratavam da atuação do nutricionista no âmbito do SUS no ementário dessas disciplinas do PPC. Por merecerem uma análise específica em função de sua complexidade enquanto estratégia de ensinoaprendizagem, as ementas dos estágios curriculares não foram analisadas, assim como foram excluídas as disciplinas optativas.

Durante as leituras do PPC, foram identificadas as unidades de registro que se relacionavam às competências gerais descritas nas DCN, consideradas como categorias de análise, possibilitando a relação entre o ementário das disciplinas e o desenvolvimento de competências gerais, quais sejam: Atenção à Saúde, Tomada de Decisões, Comunicação, Educação Permanente, Liderança, Administração e Gerenciamento.

\section{Resultados}

A partir das leituras detalhadas de todas as ementas do PPC, selecionou-se um grupo de disciplinas cujos conteúdos descritos nas ementas se relacionavam diretamente às atividades previstas para o nutricionista na área da Saúde Coletiva; essas atividades foram divididas em grupos (Alimentação e Nutrição em políticas e programas sociais, Atenção Básica e Vigilância Sanitária), em conformidade com a Resolução CFN 380/2005. Os resultados são apresentados no Quadro 1.

Esta análise inicial resultou na identificação de 15 disciplinas cujas ementas foram submetidas a uma análise de conteúdo, com as categorias de análise predefinidas a partir das competências gerais descritas nas DCN. Os resultados são apresentados na Tabela 1, com descrição da carga horária do somatório das disciplinas atribuídas a cada competência.

Quadro 1. Relação das disciplinas identificadas como tendo articulação com o campo da Saúde Coletiva, conforme Resolução CFN 380/2005

\begin{tabular}{|c|c|c|c|}
\hline \multirow[t]{2}{*}{ DISCIPLINAS } & \multicolumn{3}{|c|}{$\begin{array}{l}\text { Atividades previstas para o nutricionista na área da Saúde Coletiva } \\
\text { conforme Resolução CFN 380/2005 }\end{array}$} \\
\hline & $\begin{array}{l}\text { Alimentação e } \\
\text { Nutrição em políticas } \\
\text { e programas sociais }\end{array}$ & $\begin{array}{l}\text { Atenção Básica } \\
\text { (Assistência e } \\
\text { Promoção à Saúde) }\end{array}$ & Vigilância Sanitária \\
\hline Introdução à Epidemiologia & & & \\
\hline Ciências Sociais & & & \\
\hline Políticas e Práticas Saúde Coletiva & & & \\
\hline Epidemiologia Aplicada & & & \\
\hline Avaliação Nutricional & & & \\
\hline Microbiologia de Alimentos & & & \\
\hline Nutrição e Dietética I & & & \\
\hline Nutrição e Dietética II & & & \\
\hline Nutrição Materno-Infantil & & & \\
\hline Patologia da Nutrição e Dietoterapia I & & & \\
\hline Nutrição Social I & & & \\
\hline Educação Nutricional & & & \\
\hline Nutrição Social II & & & \\
\hline Patologia da Nutrição e Dietoterapia II & & & \\
\hline Nutrição Social III & & & \\
\hline
\end{tabular}


Tabela 1. Unidades de registro de conteúdo das ementas e número de disciplinas relacionadas a cada competência geral, com distribuição de carga horária.

\begin{tabular}{lccc}
\hline \multicolumn{1}{c}{$\begin{array}{c}\text { Competências } \\
\text { gerais }\end{array}$} & $\begin{array}{c}\text { Número de Unidades } \\
\text { de Registro }\end{array}$ & $\begin{array}{c}\text { Número de } \\
\text { disciplinas }\end{array}$ & $\begin{array}{c}\text { Carga Horária Total } \\
\text { (Teórica - T; Prática - P) }\end{array}$ \\
\hline Atenção à saúde & 63 & 13 & 915 horas/aula (630T/ 285P) \\
Tomada de decisões & 12 & 7 & 390 horas/aula (240T/ 150P) \\
Comunicação & 3 & 3 & 150 horas/aula (105T/45P) \\
Administração e gerenciamento & 3 & 3 & 195 horas (105T/ 90P) \\
Liderança & Nenhum & Nenhuma & - \\
Educação permanente & Nenhum & Nenhuma & - \\
\hline
\end{tabular}

É importante destacar que uma mesma ementa de disciplina pode ter gerado registros atribuídos a categorias diferentes; porém, cada unidade de registro foi atribuída a uma única categoria. Para a identificação das unidades de registro, foi considerado cada item descrito na ementa, podendo ser uma frase inteira ou termos separados como subitens, com um sentido específico e completo.

Procurando detalhar melhor os dados encontrados, utilizou-se a mesma divisão das disciplinas utilizada no PPC para identificar a relação das competências gerais por área, conforme é apresentado no Quadro 2.

Buscando observar o desenvolvimento das competências gerais ao longo dos períodos do curso, procedeu-se a uma análise que utilizou as categorias predefinidas, a partir das unidades de registro identificadas nas ementas, que foram relacionadas a cada período do curso de acordo com as disciplinas selecionadas. Esta análise é apresentada no Gráfico 1.

Quadro 2. Disciplinas identificadas por registros de conteúdos nas ementas, com distribuição em grupos por áreas, conforme PPC analisado.

\begin{tabular}{|c|c|c|c|}
\hline Competências gerais & $\begin{array}{c}\text { Ciências Sociais, Humanas e } \\
\text { Econômicas }\end{array}$ & $\begin{array}{c}\text { Ciências da Alimentação } \\
\text { e Nutrição }\end{array}$ & $\begin{array}{c}\text { Ciências } \\
\text { dos Alimentos }\end{array}$ \\
\hline Atenção à Saúde & $\begin{array}{l}\text { Introdução à Epidemiologia } \\
\text { Ciências Sociais } \\
\text { Políticas e Práticas de Saúde } \\
\text { Coletiva }\end{array}$ & $\begin{array}{l}\text { Avaliação Nutricional } \\
\text { Nutrição e Dietética I } \\
\text { Nutrição e Dietética II } \\
\text { Nutrição Materno-Infantil } \\
\text { Patologia Nutr. Dietoterapia I } \\
\text { Nutrição Social I } \\
\text { Educação Nutricional } \\
\text { Nutrição Social II } \\
\text { Patologia Nutr. Dietoterapia II }\end{array}$ & Microbiologia de Alimentos \\
\hline Tomada de decisões & Introdução à Epidemiologia & $\begin{array}{l}\text { Nutrição e Dietética II } \\
\text { Nutrição Social I } \\
\text { Educação Nutricional } \\
\text { Nutrição Social II } \\
\text { Nutrição Social III }\end{array}$ & Microbiologia de Alimentos \\
\hline Comunicação & $\begin{array}{l}\text { Introdução à Epidemiologia } \\
\text { Ciências Sociais }\end{array}$ & Educação Nutricional & \\
\hline Administração e Gerenciamento & Epidemiologia Aplicada & $\begin{array}{l}\text { Nutrição Materno-Infantil } \\
\text { Nutrição Social III }\end{array}$ & \\
\hline Liderança & - & - & \\
\hline Educação Permanente & - & - & - \\
\hline
\end{tabular}




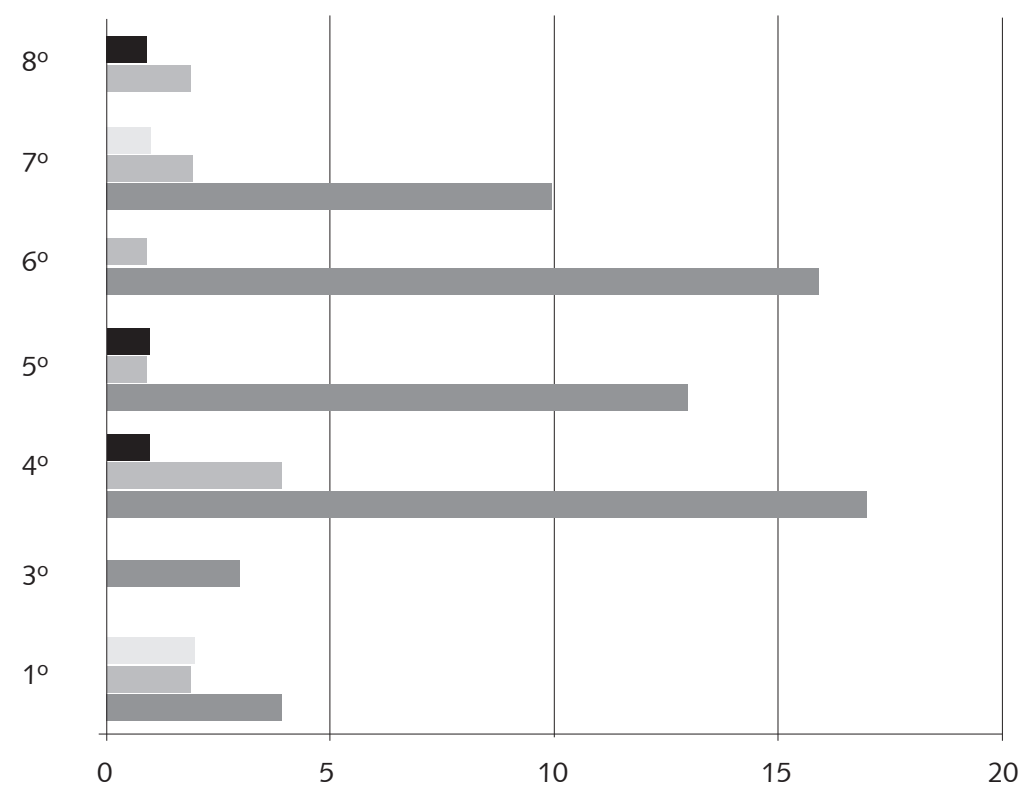

Administração e Gerenciamento Comunicação

Tomada de decisões

Atenção à Saúde

Gráfico 1. Distribuição do número de registros por períodos do curso, de acordo com as competências identificadas

Os dados apresentados permitem visualizar, a cada período, quais competências estão previstas para serem desenvolvidas pelos estudantes do curso a partir das ementas das disciplinas selecionadas. Vale ressaltar que os estágios curriculares, realizados no $9^{\circ}$ período do curso, não foram objeto de análise neste estudo.

\section{Discussão}

A análise do PPC estudado permitiu observar pouca articulação entre as DCN e a Resolução CFN380/2005, quando se relacionaram as competências gerais dos profissionais de saúde com as atribuições do nutricionista no campo da Saúde Coletiva. Ainda assim, foi possível estabelecer alguns parâmetros que permitiram definir um grupo de disciplinas e analisá-las a partir da utilização das competências gerais como categorias. Este grupo correspondeu a 1020 horas totais, ou seja, 32,5\% das 3135 horas/aula do PPC analisado, considerando apenas a carga horária das disciplinas (sem os estágios curriculares e as atividades formativas).

Este resultado está próximo daquele encontrado no estudo de Recine et al. ${ }^{9}$, que foi realizado mediante envio de questionários a todas as instituições do país, públicas e privadas, que ofertavam cursos de Nutrição, visando caracterizar a formação em saúde pública nos cursos de graduação em Nutrição no Brasil. Dentre os resultados, foi observado um percentual de horas/aula destinado às disciplinas de Saúde Pública (considerando apenas as obrigatórias), entre 12 e 44,5\%; a maioria dos cursos, 72,2\%, destinou, no máximo, 30\% da carga horária total para as disciplinas consideradas da área de Nutrição e Saúde Pública.

Entre os principais achados deste estudo, podemos destacar algumas lacunas importantes no PPC percebidas por meio da análise das ementas, quando se estabelecem as competências como parâmetro de análise. Das competências gerais, conforme as DCNs, "Liderança" e "Educação Permanente" 
não foram contempladas nos conteúdos de nenhuma das ementas das disciplinas selecionadas. Em se tratando especificamente da "Educação Permanente", a mesma se refere, conforme as DCN, à capacidade de aprender continuamente, tanto na sua formação quanto na sua prática, o que implica um compromisso com a sua própria educação ${ }^{6}$. Também é característica do SUS a articulação com a educação permanente, havendo, para isto, uma política específica ${ }^{15}$.

No caso da Saúde Coletiva, considerando especificamente as duas competências acima citadas, torna-se necessário ressaltar que, pelos princípios e diretrizes do SUS, o trabalho em equipe é fundamental para a atuação dos profissionais no atual modelo de atenção à saúde, o que envolve o desenvolvimento de algumas competências, entre elas, a "Liderança". No contexto do trabalho em equipe multiprofissional, tendo em vista o bem-estar da comunidade e considerando a "Liderança" entre as competências gerais para o nutricionista, não se observa a sua materialização na atuação profissional, e não se discute uma perspectiva de liderança nos dispositivos legais que regulam a profissão ${ }^{5}$, ou em documentos que orientam para ações específicas de alimentação e nutrição na atenção básica ${ }^{16,17}$. Esse desencontro entre as $\mathrm{DCN}$ e os demais documentos que inspiram a formação do profissional de Nutrição se reflete no PPC analisado, que, de acordo com os dados apresentados, não destina esforços para desenvolver competências de liderança no aluno dentro do campo da Saúde Coletiva.

Como a análise ficou restrita às disciplinas que se articulavam com as atribuições do nutricionista no campo da Saúde Coletiva, em conformidade com a resolução CFN 380/2005, nossa análise não permite afirmar a não-existência de conteúdos nas ementas das demais disciplinas que tratem dessas duas competências no PPC. Considerando, porém, que algumas dessas disciplinas estão associadas às outras áreas de atuação do profissional como, por exemplo, a Educação Nutricional, é possível que as mesmas lacunas observadas no PPC em relação à área de Saúde Coletiva possam estar presentes na formação referente às outras áreas de atuação.

Outra lacuna que merece destaque é a ausência de conteúdos da disciplina de Ética Profissional articulados com o campo da Saúde Coletiva, o que fica demonstrado pela não-inclusão desta disciplina no grupo selecionado. Considerando a atual política de saúde, com incorporação de temas transversais como a humanização do cuidado, a formação do nutricionista deveria envolver tanto o conhecimento do arcabouço teórico do SUS quanto as demandas atuais do sistema de saúde, com valorização dos postulados éticos e de cidadania.

Outra competência analisada a ser ressaltada é a "Comunicação" que, enquanto registro de conteúdo nas ementas, aparece em apenas três disciplinas, sendo duas do primeiro ano do curso, com pouca carga horária prática, e na disciplina de Educação Nutricional, do $7^{\circ}$ período. Se considerarmos que esta competência possa ser articulada à Educação Nutricional, e sendo esta de grande importância na constituição do nutricionista como profissional de saúde, permeando todos os campos de atuação, a "Comunicação" como competência deveria ser mais enfatizada e estar presente em toda a formação. Conforme Boog ${ }^{11}$, as novas competências exigem do nutricionista uma formação para a atuação como educador em saúde, o que leva à necessidade de um redirecionamento dos cursos, pois o caráter muito biológico da formação ainda constitui o denominador comum. A formação como educador não se dá em apenas uma disciplina, mas é uma responsabilidade do curso e de todos os seus docentes.

Quando se analisam as disciplinas em grupos por área, como previsto nas DCN e no PPC, é importante citar o estudo de Bosi e Prado ${ }^{18}$, que discutem a constituição e o reconhecimento de, pelo menos, três principais núcleos de práticas para o profissional de Nutrição: (1) "Nutrição Clínica", "Dietoterapia" ou "Terapia Nutricional"; (2) "Administração de Serviços de Alimentação, Produção de Refeições ou Alimentação de Coletividades"; (3) "Nutrição em Saúde Pública", "Nutrição Social (e Aplicada)" ou "Nutrição em Saúde Coletiva". Segundo as autoras, neste último grupo, estariam os núcleos constitutivos da Saúde Coletiva.

No estudo realizado, observamos a divisão das disciplinas em grupos por área, conforme proposto nas DCN, mas com uma distribuição de conteúdos ainda não totalmente articulada com o campo de prática profissional. Quando se analisa o PPC, é possível verificar certos conflitos na alocação de algumas disciplinas em grupos diferenciados por área, como o fato de a Epidemiologia estar no grupo das Ciências Humanas, Sociais e Econômicas, e as disciplinas de Nutrição Social no mesmo 
grupo das disciplinas da Nutrição Clínica. Esta divisão pode levar à compreensão da existência de um percentual satisfatório de conteúdos em um determinado grupo, como, por exemplo, o grupo das Ciências Humanas e Sociais; porém, na verdade, este grupo agrega conteúdos que estariam mais bem posicionados em outros grupos de disciplinas, como é o caso da Epidemiologia. Chama a atenção, também, o fato de haver poucos conteúdos relacionados à competência "Administração e Gerenciamento" e, quando identificados, parte deles estar no grupo das Ciências Sociais e Humanas, onde foram acopladas as Ciências Econômicas. Portanto, a divisão das disciplinas em grupos por área carece de maior reflexão, tendo em vista a delimitação dos campos de prática profissional.

Em se tratando da carga horária das disciplinas selecionadas, observamos que, do total de carga horária do PPC, aproximadamente 33\% da carga horária contêm um ou mais conteúdos relacionados às competências gerais. Embora esta análise não distinga o número de horas/aula destinado a cada conteúdo, de um modo generalizado permite observar que as competências estão representadas em boa parte das ementas. Destas, a mais contemplada foi a "Atenção à Saúde", para a qual foram considerados todos os conteúdos que envolvem conhecimentos e habilidades necessárias à atuação do nutricionista tanto na atenção individual quanto coletiva. Esta competência foi, também, a mais bem distribuída entre os períodos. A segunda competência mais contemplada foi a "Tomada de Decisão", onde se considerou a aplicação do conhecimento em área de atuação específica do nutricionista; esta competência mostrou-se mais bem contemplada entre os conteúdos das ementas das disciplinas do quarto período, e não nos últimos, como seria esperado.

Considerações podem ser feitas quanto à definição dos conteúdos em relação às categorias de análise, considerando as duas competências acima citadas. A amplitude dos termos utilizados nas DCN para se referir às duas competências gerais citadas tornou difícil, muitas vezes, a alocação dos conteúdos, resultando em uma análise que poderá ser confrontada, futuramente, com novos estudos e em diferentes perspectivas. Tal dificuldade reflete alguns debates já feitos por autores que discutiram as competências para o nutricionista a partir das definições empregadas nas DCN, como o importante estudo de Soares e Aguiar ${ }^{19}$.

Sobre a adequação de projetos pedagógicos às $\mathrm{DCN}$, estudo realizado em uma instituição de ensino do Distrito Federal, analisando o projeto pedagógico do curso de Nutrição e as ementas disciplinares, demonstrou a presença de conteúdos específicos preconizados pelas DCN durante todo o curso, assim como o perfil e as competências esperadas para os egressos; porém, a matriz curricular mostrou-se frágil em outros aspectos, como o desenvolvimento de atividades interdisciplinares e práticas nos semestres iniciais, e na articulação com programas e políticas públicas ${ }^{20}$.

No Brasil, ainda há pouca literatura produzida a respeito do desenvolvimento das habilidades e competências aqui descritas. Recentemente, foi desenvolvido o Consenso "Habilidades e Competências do Nutricionista em Saúde Coletiva", sendo fruto de um estudo do Observatório de Políticas de Alimentação e Nutrição (OPSAN) da Universidade Federal de Brasília, com participação da Organização Panamericana de Saúde (OPAS) e da Coordenação Geral de Alimentação e Nutrição do Departamento de Atenção Básica da Secretaria de Atenção à Saúde do Ministério da Saúde. Este documento deixa clara a existência de diversas lacunas na formação do nutricionista e mostra a necessidade de revisão do processo de ensino-aprendizagem, além de alertar para a importância da ampliação urgente dos campos de prática ${ }^{21}$.

O documento acima citado estabelece várias prioridades necessárias para o aprimoramento da formação profissional. Entre estas, destacamos: desenvolver habilidades, atitudes e conhecimento de nutrição dos indivíduos e comunidades; desenvolver estratégias de educação continuada em alimentação e nutrição a profissionais de outras áreas, como educação, desenvolvimento social, Segurança Alimentar e Nutricional, entre outros; desenvolver estratégias de educação continuada em alimentação e nutrição aos profissionais de saúde; participar de processos de desenvolvimento de lideranças e organizações locais envolvidas na agenda, programas e ações de alimentação e nutrição ${ }^{21}$. 
O nosso estudo procurou levantar alguns aspectos específicos sobre a formação do nutricionista, destacando a atuação na área da Saúde Coletiva, utilizando como foco a análise de um PPC em relação às $D C N$. Os resultados encontrados permitiram ampliar algumas discussões atuais sobre a formação do nutricionista frente às áreas de atuação profissional, confirmando a percepção de lacunas existentes, bem como de algumas ambiguidades, o que aponta para a necessidade de revisão dos projetos pedagógicos frente às demandas da formação profissional. Também foi possível refletir sobre alguns parâmetros utilizados na definição das competências do nutricionista em conformidade com as DCN, o que permite suscitar novas discussões sobre a utilização das mesmas como instrumento de orientação para a formação acadêmica do nutricionista.

É importante também considerar que as competências gerais aqui estudadas foram definidas em função de objetivos educacionais que permeiam a formação dos profissionais de saúde no país, de acordo com o modelo de saúde implantado, não se referindo, especificamente, à atuação do nutricionista. Cabe, portanto, às instituições de Ensino Superior refletirem sobre esta formação, considerando as características do atual sistema de saúde, que prevê, entre outros aspectos, o trabalho em equipe multiprofissional.

\section{Limitações do estudo}

O estudo foi feito considerando as ementas das disciplinas conforme registro no PPC, por se tratar de um estudo documental. Portanto, os planos de ensino não foram analisados, o que poderia modificar, profundamente, a análise procedida. Também não foram consideradas as estratégias pedagógicas utilizadas pelos docentes, por estas não terem sido objeto de estudo.

Porém, vale ressaltar que este estudo permitiu uma análise do documento que serve de base para a construção dos planos de ensino, no caso o PPC. Embora possamos considerar que um plano de ensino permite ampliar os conteúdos de uma determinada disciplina, a partir tanto das estratégias pedagógicas quanto dos demais recursos empregados, espera-se que as ementas tragam, resumidamente, todos os conteúdos que, prioritariamente, devam nortear a construção do processo ensino-aprendizagem. Portanto, o estudo, a partir das ementas, permite identificar elementos prioritários para o ensino de uma dada disciplina.

Como já abordado, houve dificuldade em se identificar registros que caracterizassem algumas competências, como a "Atenção à Saúde" e a "Tomada de Decisões", devido à complementariedade das ações associadas às duas competências. Assim, foram discriminadas da seguinte forma: para a competência "Atenção à Saúde", foram considerados todos os conteúdos que envolvem conhecimentos e habilidades necessárias à atuação do nutricionista tanto na atenção individual quanto coletiva; para a "Tomada de Decisão", considerou-se a aplicação do conhecimento em área de atuação específica do nutricionista. Ainda assim, as pesquisadoras consideram a existência de fragilidades nesta classificação, o que denota um caráter ambíguo na definição dessas competências para o nutricionista.

Ao se considerar a carga horária, é importante ressaltar que cada disciplina traz determinados conteúdos a serem ministrados ao longo do semestre, não sendo possível identificar quantas horas/ aulas estão sendo empregadas para o desenvolvimento de cada competência aqui relatada.

O estágio curricular não foi analisado em função de suas características próprias, considerando, também, que o local de realização do estágio pode possibilitar ou não o desenvolvimento de determinadas competências ou habilidades.

Por fim, o estudo não pretende esgotar o tema da análise da formação do nutricionista frente ao desenvolvimento de competências que permitam a sua atuação profissional na área da Saúde Coletiva, mas pretende contribuir para a reflexão sobre esta questão, dando ênfase a uma formação profissional que atenda às necessidades do SUS, com vistas à integralidade da atenção. 


\section{Colaboradores}

Os autores participaram, igualmente, de todas as etapas de elaboração do artigo.

\section{Referências}

1. Mendes EV. 25 anos do Sistema Único de Saúde: resultados e desafios. Estud Av. 2013; 27(78):27-34.

2. Ministério da Saúde. Política Nacional de Atenção Básica [Internet]. Brasília (DF): Ministério da Saúde; 2006 [acesso 2013 Mar 14]. Disponível em: http://bvsms.saude.gov. br/bvs/publicacoes/politica_nacional_atencao_basica_2006.pdf

3. Scherer MDA, Pires DEP, Jean R. A construção da interdisciplinaridade no trabalho da Equipe de Saúde da Família. Cienc Saude Colet. 2013; 18(11):3203-12.

4. Cervato-Mancuso AM, Tonacio LV, Silva ER, Vieira VL. A atuação do nutricionista na Atenção Básica à Saúde em um grande centro urbano. Cienc Saude Colet. 2012; 17(12):3289-300.

5. Conselho Federal de Nutricionistas. Resolução CFN 380/2005, de 28 de dezembro de 2005. Dispõe sobre a definição das áreas de atuação do nutricionista e suas atribuições, estabelece parâmetros numéricos de referência, por área de atuação, e dá outras providências. Diário Oficial da União. 28 Dez 2005.

6. Ministério da Educação. Conselho Nacional de Educação. Câmara de Educação Superior. Resolução CNE/CES 5/2001. Institui Diretrizes Curriculares Nacionais do Curso de Graduação em Nutrição. Diário Oficial da União. 9 nov. 2001. Seção 1:39.

7. Ministério da Saúde. Secretaria de Atenção à Saúde. Departamento de Atenção Básica. Política Nacional de Alimentação e Nutrição. 2a ed. Brasília (DF): MS; 2012. (Série B, Textos Básicos de Saúde).

8. Perrenoud P. Construir as competências desde a escola. Porto Alegre: Artmed ; 1999.

9. Recine E, Gomes RCF, Fagundes AA, Pinheiro ARO, Teixeira BA, Souza JS, et al. A formação em saúde pública nos cursos de graduação de nutrição no Brasil. Rev Nutr. 2012; 25 (1):21-33.

10. Geraldi CMG. Do pessimismo da razão para o otimismo da vontade: referências para a construção dos projetos pedagógicos nas IES brasileiras. In: Fórum de Pró-Reitores de Graduação das Universidades Brasileiras; 1999; Curitiba; Brasil [Internet]. Curitiba; 1999 [acesso 2014 Nov 10]. Disponível em: http://www.forgrad.com.br/antigo/publicacoes. php

11. Boog MCF. Atuação do nutricionista em saúde pública na promoção da alimentação saudável. Cienc Saude (Porto Alegre). 2008; 1(1):33-42.

12. Lakatos EM, Marconi MA. Fundamentos de metodologia científica. 7a ed. São Paulo: Atlas; 2010.

13. Lakatos EM, Marconi M A. Metodologia científica. 4a ed. São Paulo: Atlas; 2006.

14. Bardin L. Análise de conteúdo. Lisboa: Edições 70; 1977.

15. Ministério da Saúde. Secretaria de Gestão do Trabalho e da Educação na Saúde. Departamento de Gestão da Educação em Saúde. Política Nacional de Educação Permanente em Saúde. Brasília (DF): MS; 2009. (Série B, Textos Básicos de Saúde). (Série Pactos pela Saúde 2006, 9).

16. Conselho Federal de Nutricionistas. Sistema Conselhos Federal e Regionais de Nutricionistas. O Papel do Nutricionista na Atenção Primária à Saúde [Intenet]. Brasília (DF); 16 de outubro de 2008 [acesso 2014 Set 10]. Disponível em: http://www.cfn.org. br/eficiente/repositorio/cartilhas/61.pdf. 
17. Ministério da Saúde. Secretaria de Atenção à Saúde. Departamento de Atenção Básica. Matriz de ações de alimentação e nutrição na atenção básica de saúde. Brasília (DF): MS, 2009. (Série A. Normas e Manuais Técnicos).

18. Bosi MLM, Prado SD. Alimentação e Nutrição em Saúde Coletiva: constituição, contornos e estatuto científico. Cienc Saude Colet. 2011; 16(1):7-17.

19. Soares NT, Aguiar AC. Diretrizes curriculares nacionais para os cursos de nutrição: avanços, lacunas, ambiguidades e perspectivas. Rev Nutr. 2010; 23(5):895-905.

20. Brito JP. Adequação da matriz curricular da graduação em nutrição às diretrizes curriculares nacionais em uma instituição de ensino superior do Distrito Federal [monografia ]. Brasília (DF): Universidade de Brasília; 2010.

21. Recine E, Mortoza AS. Consenso sobre habilidades e competências do nutricionista no âmbito da saúde coletiva. Brasília (DF): Observatório de Políticas de Segurança e Nutrição; 2013.

Alves CGL, Martinez MR. Lagunas entre la formación del nutricionista y el perfil de competencias para actuación en el Sistema Brasileño de Salud (SUS). Interface (Botucatu). 2016; 20(56):159-69.

La actuación del nutricionista en el Sistema Brasileño de Salud (SUS) envuelve actividades de alimentación y nutrición en políticas y programas institucionales, de atención básica y vigilancia sanitaria, con la previsión de desarrollar competencias generales y específicas en la formación académica, conforme las Directrices Curriculares Nacionales (DCN). Partiéndose del análisis de un Proyecto Pedagógico de Curso (PPC), se reflexionó sobre la formación del nutricionista y su alineamiento con las directrices que rigen la profesión y su actuación en el SUS. Se seleccionaron y sometieron al análisis de contenido que reveló lagunas relacionadas con la presencia o no de determinados contenidos en las enmiendas, 15 asignaturas del campo de la Salud Colectiva. El PPC no identificó las competencias "liderazgo" y "educación permanente", aunque ellas son necesarias para la formación del nutricionista. En conclusión, los elementos presentados podrán regir los currículos de Nutrición enfocados en una formación para la actuación en el SUS.

Palabras clave: Proyecto pedagógico. Nutrición. Competencias. Directrices curriculares. 
